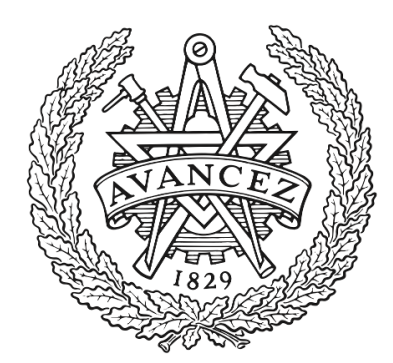

\title{
CHALMERS
}

UNIVERSITY OF TECHNOLOGY

\section{Time-Domain Protection and Fault Location of Wye-Connected Shunt Capacitor Banks Using Superimposed Current and Differential Voltage}

Downloaded from: https://research.chalmers.se, 2023-04-26 00:37 UTC

Citation for the original published paper (version of record):

Mohanty, R., Pradhan, A. (2021). Time-Domain Protection and Fault Location of Wye-Connected Shunt Capacitor Banks Using

Superimposed Current and Differential Voltage. IEEE Transactions on Power Delivery, 36(6):

3486-3495. http://dx.doi.org/10.1109/TPWRD.2020.3043693

N.B. When citing this work, cite the original published paper.

(O2021 IEEE. Personal use of this material is permitted.

However, permission to reprint/republish this material for advertising or promotional purposes 


\title{
Time-Domain Protection and Fault Location of Wye-Connected Shunt Capacitor Banks Using Superimposed Current and Differential Voltage
}

\author{
Rabindra Mohanty, Member, IEEE, Ashok Kumar Pradhan, Senior Member, IEEE
}

\begin{abstract}
This paper presents protection and fault location of wye-connected shunt capacitor banks used in medium or high voltage applications. The proposed method is sensitive to single element failure obtained by using voltage adaptive instantaneous superimposed current in each phase. The change in equivalent reactance computed using time-domain signals is used to find the number of failed capacitor element and types of fault. The location of the faulted capacitor is identified using sign of the voltage difference of the lower and upper halves of the shunt capacitor bank. The performance of the proposed method is tested for various cases including identical faults, simultaneous faults, system voltage unbalance in both single and double wyeconnected shunt capacitor banks. The method is also validated using field data collected from a $400 \mathrm{kV} \mathrm{SCB}$ for an internal fault. The proposed technique is compared with available methods and found accurate.
\end{abstract}

Index Terms-Capacitor bank connections, short circuit and open circuit faults, shunt capacitor bank, time-domain protection.

\section{INTRODUCTION}

$\mathbf{S}$ HUNT capacitor banks (SCBs) are used in electric power systems as an economical solution for reactive power support, power factor improvement and enhancement of steady state power transmission capacity [1], [2]. The SCB resides a large number of capacitor elements, typically in the range of several hundreds to a couple of thousands. The capacitor elements are connected in series and parallel to form a bank, and the number of elements in series and parallel depends on the voltage and reactive power rating of the bank. Failure of a capacitor element causes voltage stress and overcurrent in remaining elements in the SCB [3]. Such an event may lead to damage the dielectric material of healthy elements that may further cause the hazard of explosion or fire. Therefore, a sensitive protection of SCB is required that provides reliable and efficient operation. Further, the idea of location and number of faulted capacitor elements help in expedition of maintenance process and fast service restoration of the SCB.

Depending on the applications and voltage level, SCBs are available in different types of connection including single wye (Y)-grounded, single Y-ungrounded, double Y-grounded, double Y-ungrounded, H-bridge and delta connected SCBs [4]-[7]. However, single/double Y-grounded/ungrounded

R. Mohanty is with the division of Electric Power Engineering, department of Electrical Engineering, Chalmers University of Technology, Gothenburg, Sweden 41296 (e-mail: rabindra@ chalmers.se)

A. K. Pradhan is with the department of Electrical Engineering, Indian Institute of Technology Kharagpur, India 712302 (e-mail: akpradhan@ee.iitkgp.ernet.in)
SCBs are widely used in medium and high voltage applications [2]. In the previous work on SCB protections, methods in [1]-[4], [8]-[12] identify the internal failure of elements, faulted leg and faulted phase in the SCB. All these existing methods can be categorized into phase voltage differential, neutral voltage unbalance, phase current unbalance, neutral current unbalance and per phase equivalent reactance based protections. However, the fault detection with low sensitivity is a concern of available methods. Further, the location of faulted element in a phase is not yet determined.

Most of the available SCB protections are based on voltage and current phasors, which need a cycle to estimate accurate phasors during fault. The current drawn by the SCB depends on terminal voltage and therefore, the protection decision using phasors is influenced by the voltage variation which is not being accounted. For transmission line, time-domain approach provides sensitive and faster protection [13], [14]. Using the principle of superposition, any network with fault can be analyzed separately with the prefault network to obtain voltage and current of load components and the faulted network for the fault-generated components [13], [15]. The motivation of this paper is to use such an approach in time-domain for sensitive and faster SCB protection.

In this paper, three features collectively provide the protection and fault location of Y-connected SCB. An instantaneous superimposed current based fault identification technique is proposed. This current is obtained by subtracting the calculated phase current in SCB using phase voltage and healthy capacitance value at that time from the measured fault current. This provides a faster way for capacitor failure identification adapt to the system voltage variation even during fault. The number of capacitor elements failed in the SCB during the fault is obtained using change in equivalent reactance per phase, being calculated using sample values of signals. The positive and negative changes in equivalent reactance correspond to open and short circuit faults in SCB respectively. Using the midpoint transient voltage, the method is able to identify the location of faulted element in upper or lower half of the SCB. The main contributions of the work for SCB protection are on:(i) voltage adaptive sensitive protection (up to element level), (ii) identification of exact number of faulted elements/units, (iii) classifying open circuit and short circuit faults in the SCB and (iv) locating failed element in the upper or lower half of SCB.

The measurements used in the proposed method are limited to traditional phase voltages and currents, neutral and mid- 
point tap voltages [4], [5]. The performance of the proposed method is tested for Y-connected SCB for various conditions including identical faults and simultaneous faults with balanced and unbalanced terminal voltages during internal fault. Using field data from the SCB connected to $400 \mathrm{kV}$ bus in Indian grid, the method is also validated. Comparative assessments with available techniques demonstrate the superior performance of the proposed protection method for SCB.

\section{Shortcomings of AVAilable SCB Protections}

The internal faults in a SCB can be categorized into short circuit and open circuit of capacitor units/elements as shown in Fig. 1. Dielectric failure causes short circuit fault in a fuseless SCB. The fuse operation in an externally fused bank leads to open circuit faults. This section presents an overview of the

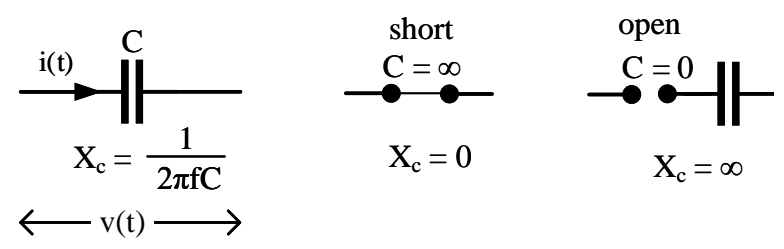

Fig. 1: Short circuit and open circuit of a capacitor.

performance of commonly used protection methods of SCB, based on phase and neutral voltage and current measurements [16]. Below, the per phase study is done for phase-a which can be extended to $\mathrm{b}$ and $\mathrm{c}$ phases.

\section{A. Phase voltage differential}

The phase voltage differential protection of SCB uses bus and tap voltages to obtain the voltage difference $V_{d i f}[5]$.

$$
V_{d i f}=\left(V_{a}-V_{n g}\right)-\left(\frac{1}{k} V_{t a}-V_{n g}\right)
$$

where $V_{a}, V_{n g}$ and $V_{t a}$ are the phasor magnitudes of phase, neutral and mid-point tap voltages respectively. The compensation factor, $k=\frac{C_{u p}}{C_{u p}+C_{l o w}}=\frac{V_{t a}}{V_{a}}$ during normal operation. $C_{u p}$ and $C_{l o w}$ are the equivalent capacitance in phase-a above and below the mid-point tap respectively. In a grounded Yconnected SCB, $V_{n g}=0$ in (1). The voltage difference, $V_{d i f}$ is zero for open or short circuit of same number of capacitor elements above and below the tap in a phase and thus, fails to detect such identical faults.

\section{B. Neutral voltage unbalance (NVU)}

In a strong grid where the voltages remain balanced, the neutral voltage unbalance protection is the simplest method to identify a fault in an ungrounded SCB [6]. In such a case, the neutral voltage $V_{n g}$ is ideally zero. A change in capacitance of any phase of the bank will result in SCB unbalance and a nonzero $V_{n g}$. The external unbalance is avoided using voltages in each phase and neutral to ground as in (2).

$$
N V U=V_{n g}-V_{0}-\left(K_{1}\left(V_{n g}-V_{b}\right)+K_{2}\left(V_{n g}-V_{c}\right)\right)
$$

TABLE I: Application of different SCB protections [5]

\begin{tabular}{|l|c|c|c|c|}
\hline \multirow{2}{*}{$\begin{array}{c}\text { Connections } \\
\text { of SCB }\end{array}$} & \multicolumn{4}{|c|}{ Available protection methods } \\
\cline { 2 - 5 } & $\begin{array}{c}\text { Phase } \\
\text { voltage } \\
\text { differential } \\
\text { (87V) }\end{array}$ & $\begin{array}{c}\text { Neutral } \\
\text { voltage } \\
\text { unbalance } \\
\text { (59N) }\end{array}$ & $\begin{array}{c}\text { Phase } \\
\text { current } \\
\text { unbalance } \\
\text { (60) }\end{array}$ & $\begin{array}{c}\text { Neutral } \\
\text { current } \\
\text { unbalance } \\
\text { (60N) }\end{array}$ \\
\hline $\begin{array}{l}\text { Single Y } \\
\text { grounded }\end{array}$ & $\checkmark$ & $\checkmark$ & & $\checkmark$ \\
\hline $\begin{array}{l}\text { Single Y } \\
\text { ungrounded }\end{array}$ & $\checkmark$ & $\checkmark$ & $\checkmark$ & $\checkmark$ \\
\hline $\begin{array}{l}\text { Double Y } \\
\text { grounded }\end{array}$ & $\checkmark$ & & $\checkmark$ & $\checkmark$ \\
\hline $\begin{array}{l}\text { Double Y } \\
\text { ungrounded }\end{array}$ & $\checkmark$ & $\checkmark$ & & \\
\hline
\end{tabular}

where $K_{1}$ and $K_{2}$ are $\frac{Z_{b}-Z_{a}}{3 Z_{b}}$ and $\frac{Z_{c}-Z_{a}}{3 Z_{c}}$ respectively. The method is only applicable for ungrounded Y-connected SCB. In addition, it cannot identify the faulted phase.

\section{Phase current unbalance}

Phase current unbalance protection, $I_{d i f}=I_{a 1}-I_{a 2}$ is widely used in double Y-connected SCB. where $I_{a 1}$ and $I_{a 2}$ are the currents in phase-a in left and right legs of the bank respectively. The total current, $I_{a}=I_{a 1}+I_{a 2}$. However, this method cannot identify for same number of elements failed in both legs of a phase in double Y-connected SCB.

\section{Neutral current unbalance}

Neutral current unbalance protection is suitable for single Y-grounded and double Y-grounded/ungrounded SCBs, where the unbalance current is calculated using $I_{n}=I_{a}+I_{b}+I_{c}$ and $I_{n \_d i f}=I_{n 1}-I_{n 2}$. The method cannot find the faulted phase and provides the protection of entire bank. In addition, it fails to detect identical faults in the SCB.

The aforementioned methods have shortcomings/limitations in their applications for different connections of SCB. Table I provides the available SCB protection and their applications. Although the phase voltage differential protection is applicable to all types, but it has limitation as mentioned. Further, the shortcomings during identical faults are not addressed. The identical faults in a SCB includes same number of capacitor failure above and below the mid-point, same number of element failure in all three phases, faults in both legs of a phase in double Y, failure of two phases in the left leg of double Y and failure of other phase in right leg. The proposed method addresses the above mentioned shortcomings in Y-connected SCBs.

\section{Proposed Protection Algorithms}

The proposed method uses instantaneous phase voltages and currents in time-domain for protection decision to obtain faster and high sensitivity performance compared to phasor based techniques [17]. The change in phase current in the SCB is used for fault identification and the type of fault is ensured using the sign of change in equivalent reactance of the faulted phase. Then, the voltage difference of upper and lower halves gives idea about the location of faulted capacitor. First, the change in current and voltage during fault in an element of $n$ number of capacitors connected in series and parallel is analyzed and then it is extended to the protection method proposed for SCB. 
(i) A series of capacitors for short circuit analysis: Since, $n$ capacitor elements are connected in series as shown in Fig. 2, during normal operation, the current $i_{s}(t)$ through all the elements are same and the terminal voltage $v_{s}(t)$ is divided across each element as in (3).

$$
v_{s}(t)=v_{s 1}(t)+v_{s 2}(t)+v_{s 3}(t)+v_{s 4}(t)+\ldots+v_{s n}(t)
$$

where $v_{s 1}, v_{s 2}, v_{s 3}, v_{s 4}, \ldots . v_{s n}$ are the voltage across capacitors $C_{1}, C_{2}, C_{3}, C_{4}, \ldots . C_{n}$ respectively. These voltages may not be equal at an instant due to variation in capacitance with time or the SCB is running with some failed elements. Since the same current flows through all the capacitor elements connected in series, the $i-v$ relationship can be

$$
i_{s}(t)=\left(\frac{1}{\frac{1}{C_{1}}+\frac{1}{C_{2}}+\frac{1}{C_{3}}+\frac{1}{C_{4}}+\ldots+\frac{1}{C_{n}}}\right) \frac{d v_{s}(t)}{d t}
$$

Short circuit of a capacitor element $\left(C_{4}\right.$ as in Fig. 2) results

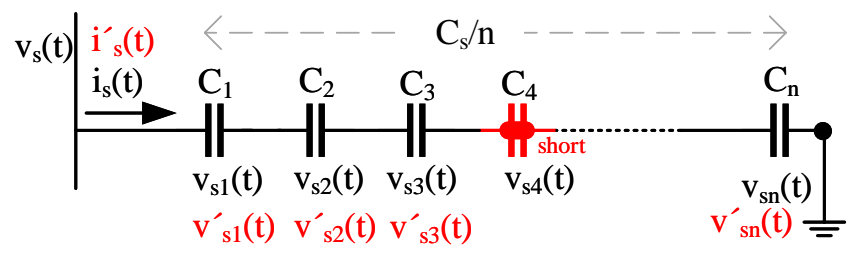

Fig. 2: Change in current and voltage for short circuit of a capacitor element.

increase in the equivalent capacitance of corresponding branch. With the same terminal voltage $v_{s}(t)$, the current through the remaining capacitors in the branch increases and thus

$$
i_{s}^{\prime}(t)=\left(\frac{1}{\frac{1}{C_{1}}+\frac{1}{C_{2}}+\frac{1}{C_{3}}+0+\ldots+\frac{1}{C_{n}}}\right) \frac{d v_{s}(t)}{d t}
$$

The voltages across remaining capacitors also increase proportionately with $i_{s}^{\prime}(t)$ or, in other words, the terminal voltage $v_{s}(t)$ will be distributed among remaining capacitors except the short circuited element $C_{4}$.

Considering equal capacitance in the branch, $C_{s}$, the corresponding $i-v$ relationship in (4) can be further simplified as

$$
i_{s}(t)=\frac{C_{s}}{n} \frac{d v_{s}(t)}{d t}
$$

During short circuit of a capacitor element, the current flows in the remaining elements as

$$
i_{s}^{\prime}(t)=\frac{C_{s}}{n-1} \frac{d v_{s}(t)}{d t}
$$

Using (6) and (7), it can be derived that

$$
i_{s}^{\prime}(t)=\frac{n}{n-1} i_{s}(t)
$$

Thus, $i_{s}^{\prime}(t)>i_{s}(t)$. With the increased current, the corresponding voltage drop across each capacitor element also increases, i.e. $v_{s 1}^{\prime}(t)=\frac{n}{n-1} v_{s 1}(t)$ and so for other elements. (ii) Capacitors in parallel for open circuit analysis: The open circuit condition is analyzed in a parallel connection of capacitor elements as depicted in Fig. 3. The total current $i(t)$ drawn by the $n$ capacitors connected in parallel is

$$
i_{p}(t)=\left(C_{1}+C_{2}+C_{3}+C_{4}+\ldots .+C_{n}\right) \frac{d v_{p}(t)}{d t}
$$

For opening of an element $\left(C_{4}\right.$ as in Fig. 3), the current drawn

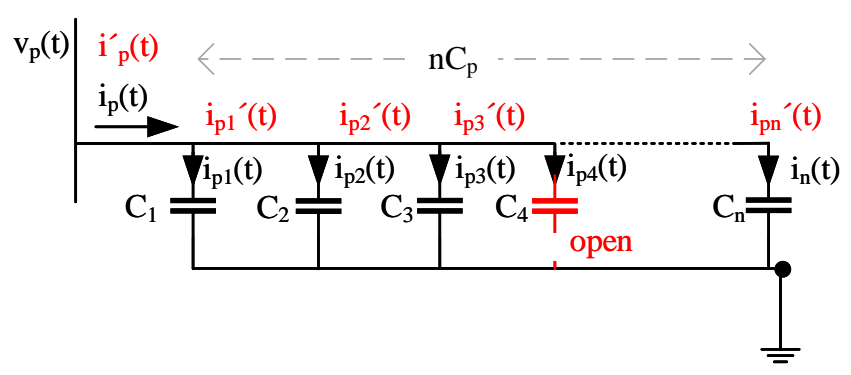

Fig. 3: Change in current for open circuit of a capacitor element.

by the remaining elements is

$$
i_{p}^{\prime}(t)=\left(C_{1}+C_{2}+C_{3}+0+\ldots .+C_{n}\right) \frac{d v_{p}(t)}{d t}
$$

From (9) and (10), it is clear that lesser current is drawn by the parallel capacitors during an open circuit. For capacitors with equal capacitance $\left(C_{p}\right)$ connected in parallel, (9) can be further simplified as

$$
i_{p}(t)=n C_{p} \frac{d v_{p}(t)}{d t}
$$

With one capacitor element open, (10) can be

$$
i_{p}^{\prime}(t)=(n-1) C_{p} \frac{d v_{p}(t)}{d t}=i_{p}(t)-C_{p} \frac{d v_{p}(t)}{d t}
$$

Thus, $i_{p}^{\prime}(t)<i_{p}(t)$.

From the above analysis, for short circuit of a capacitor connected in series, the current and voltage across remaining capacitors increase as in (8). For open circuit of a capacitor in parallel connection, the total current drawn by remaining capacitor decreases as per (12).

(iii) Protection and fault location of Y-connected SCB: A single Y-grounded/ungrounded SCB which is connected to $220 \mathrm{kV}$ system, as shown in Fig. 4 is considered. In each phase, ten groups of capacitor are connected in series with a group being parallel combination of three units. Each unit consists of three parallel branches with each branch be a series connection of six capacitor elements.

The fault current signal consists of nonfault (load) and fault-induced current signals. The difference between fault and nonfault component is the superimposed fault-induced component.

$$
\Delta i(t)=i_{f}(t)-i_{n o n_{-} f}(t)
$$

where $\Delta i$ is the instantaneous superimposed quantity, $i_{f}$ and $i_{n o n_{-} f}$ are the fault and nonfault components respectively. Generally, this nonfault component of current is considered as prefault component. In power systems, the terminal voltage 
varies continuously and therefore, the nonfault component being a function of voltage such a consideration is not appropriate in calculating $\Delta i$ using (13). In case of external disturbance, the terminal voltage of SCB changes resulting change in current drawn by the SCB. Such voltage variation due to external disturbance may result in significant $\Delta i$. Considering these in the proposed approach, the nonfault component is calculated from terminal voltage of SCB and prefault capacitor model.

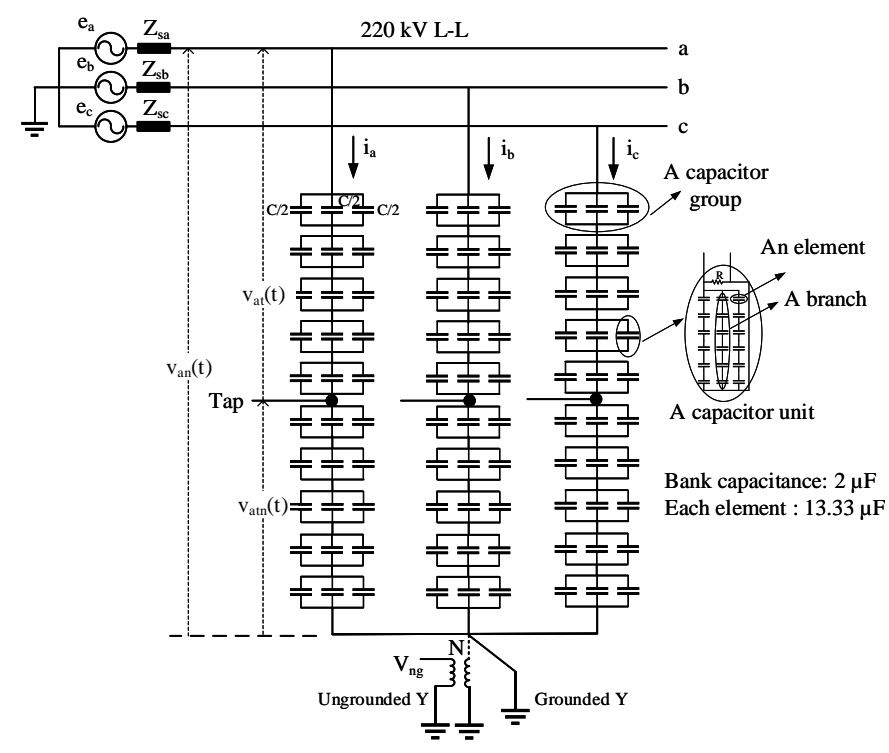

Fig. 4: A single Y-connected shunt capacitor bank.

The instantaneous superimposed current, $\Delta i(t)$ provides a sensitive fault detection approach, the change in equivalent reactance $\Delta X_{e q}$ provides the number of failed elements and voltage difference $v_{d i f}(t)$ of lower and upper halves of SCB gives the idea about location of failed element.

\section{A. Instantaneous superimposed current based fault detection}

The superimposed current is obtained using the difference of measured current and the calculated nonfault component of current. The nonfault current in phase-a (Fig. 4) is given by

$$
i_{a \_c a l}(t)=C_{a} \frac{d v_{a n}(t)}{d t}
$$

where $v_{a n}$ is the voltage of phase-a with respect to neutral, $C_{a}$ is the equivalent capacitance of phase-a in healthy condition (just before the fault). As in (7) and (12), the instantaneous current measured can be similarly expressed as

$$
i_{a \_m}(t)=C_{a}^{\prime} \frac{d v_{a n}(t)}{d t}
$$

where $C_{a}^{\prime}$ is the actual equivalent capacitance of phase-a at time t. The superimposed current can be calculated as

$$
\begin{aligned}
\Delta i_{a}(t) & =i_{a \_m}(t)-i_{a_{-} c a l}(t) \\
& =\left(C_{a}^{\prime}-C_{a}\right) \frac{d v_{a n}(t)}{d t}
\end{aligned}
$$

During normal situation, there is no change in superimposed component. Thus,

$$
\Delta i_{a}(t)= \begin{cases}0, & \text { if healthy bank } \\ \neq 0, & \text { otherwise }\end{cases}
$$

Note that in (14) and (16), the superimposed component considers variation of the terminal voltage, thus adapting to the situation. Further, the method uses updated equivalent capacitance value just before the fault in phase current calculation as in (14), thus superimposed component is not susceptible to capacitance change due to aging or temperature variation. This adaptive approach will result in accurate detection process. In addition, a threshold for $\Delta i_{a}$ of $\pm 3 \%$ of rated current is considered to deal with error and noise in measurement.

\section{B. Change in equivalent reactance for obtaining number of failed elements}

Using (16), the change in equivalent capacitance $\Delta C_{a}$ of phase-a can be expressed as

$$
\Delta C_{a}=C_{a}^{\prime}-C_{a}=\frac{\Delta i_{a}(t)}{\frac{d v_{a n}(t)}{d t}}
$$

In (17), the time-derivative of phase voltage in denominator may result in high calculation error in $\Delta C_{a}$ near the zerocrossing (small value of $\frac{d v_{a n}(t)}{d t}$ ). This error can be avoided by discarding a sample before and after the zero-crossing. The change in equivalent reactance per phase can be accurately found using the instantaneous phase voltage and current, which corresponds to the number of elements failed in the bank.

$$
\begin{array}{r}
\Delta X_{a_{-} e q}(t)=X_{a_{-} e q}^{\prime}(t)-X_{a_{-} e q}(t)=\frac{1}{\omega C_{a}^{\prime}}-\frac{1}{\omega C_{a}} \\
=\frac{1}{\omega}\left(\frac{C_{a}-C_{a}^{\prime}}{C_{a} C_{a}^{\prime}}\right)=\frac{1}{\omega}\left(\frac{-\Delta C_{a}}{\left.C_{a}^{2}+C_{a} \Delta C_{a}\right)}\right) \\
X_{a_{-} e q}(t)= \begin{cases}\text { negative, } & \text { if short circuit of capacitors } \\
\text { positive, } & \text { open circuit of capacitor }\end{cases}
\end{array}
$$

Here, $X_{a_{-} e q}$ is calculated using time-domain quantities and thus, there is no need of phasor computation. Note that, $\omega$ in (18) works as a coefficient to relate the change in reactance and the capacitance obtained from (17) for a frequency of 50 Hz. $N_{c} \approx \Delta X_{a_{-} e q}$, where $N_{c}$ corresponds to the proportionate number of elements failed in phase-a, $X_{a_{-} e q}$ and $X_{a_{-} e q}^{\prime}$ are the equivalent reactances of phase-a in healthy and faulted conditions respectively. The exact number of elements failed in the faulted phase of the SCB can be identified by manual testing at the site. The sign of $\Delta X_{a_{-} e q}$ confirms the type of failure.

\section{Instantaneous voltage of upper and lower halves for failed half identification}

The instantaneous phase-to-neutral voltage measured at phase-a (Fig. 4) is

$$
v_{a \_n}(t)=V_{\max } \sin (\omega t)
$$


The instantaneous voltage across mid-point tap and neutral is

$$
v_{a_{-} t n}(t)=\frac{V_{\max }}{2} \sin (\omega t)
$$

Mid-point tapping in a group of series capacitors provides maximum sensitivity [6]. The instantaneous voltage across the mid-point tap and phase-a is calculated as

$$
\begin{array}{r}
v_{a_{-} t}(t)=v_{a_{-} n}(t)-v_{a_{-} t n}(t) \\
=\frac{V_{\max }}{2} \sin (\omega t)
\end{array}
$$

The instantaneous voltage difference of (20) and (21) can be

$$
v_{a_{-} d i f}(t)=\left|v_{a_{-} t n}(t)\right|-\left|v_{a_{-} t}(t)\right|
$$

The |.| is used to avoid the effect of fault inception time in (positive or negative half cycle) voltage signals.

$$
\begin{aligned}
& v_{a_{-} d i f}(t)= \begin{cases}\text { negative, } & \text { if short circuit below the tap } \\
\text { positive, } & \text { short circuit above the tap }\end{cases} \\
& v_{a_{-} \text {dif }}(t)= \begin{cases}\text { negative, } & \text { if open circuit above the tap } \\
\text { positive, } & \text { open circuit below the tap }\end{cases}
\end{aligned}
$$

However, (22) is true only for SCB with mid-point tapping. In case of SCB with the tapping position other than at middle, a compensation factor $k_{t a p}$ is considered in (22) as below

$v_{a \_d i f}(t)=\left|v_{a \_t n}(t)\right|-\left|v_{a \_t}(t)\right|=2\left|v_{a \_t n}(t)\right|-\left(k_{t a p}\left|v_{a \_n}(t)\right|\right)$

where $k_{\text {tap }}=\frac{2\left|v_{a_{-} t n}(t)\right|}{\left|v_{a_{-} n}(t)\right|}$. Note that $k_{\text {tap }}$ is a calculated value at starting and does not change automatically unless it is RESET. For mid-point tapping, $k_{t a p}=1$. Tapping at $30 \%$ from neutral point, $k_{t a p}=0.6$, tapping at $70 \%$ from neutral point, $k_{t a p}=1.4$. The voltage difference $v_{a_{-} d i f}$ is continuously observed and the consistency of sign (positive or negative) for five consecutive instants provides correct identification of faulted half. Note that the type of fault is already know from (18) in step B. The flow diagram of the proposed algorithm is depicted in Fig. 5. The trip signal is generated for $N_{c}$ $>\zeta$, where $\zeta$ is the maximum number of failed elements with which the SCB can operate safely. The similar analysis is true for phase-b and phase-c using corresponding phase voltage and current to derive the protection decision and location of faulted elements in the SCB. The possible faults in the SCB considered in Fig.4 are listed in Table II. In a branch of SCB, any one or multiple elements can be short circuited individually or together. Short circuit of six elements in one branch is considered as a unit short. Being three units connected in parallel to form a group, a unit short is same as a group short. Similarly, open circuit of an element in a branch causes the entire branch open. Opening of three branches in a unit leads to the unit open. Three units in a group open means the group is opened and thus, the phase is open circuited.

The time-domain superimposed component obtained from (16) contains the transients produce by the fault. In a numerical relay, this component can be directly implemented [13]. An anti-aliasing filter is used to avoid signal aliasing. The phase voltages and currents at the SCB terminal are sampled at the rate of $1 \mathrm{MHz}$ for analog to digital conversion. Then, the

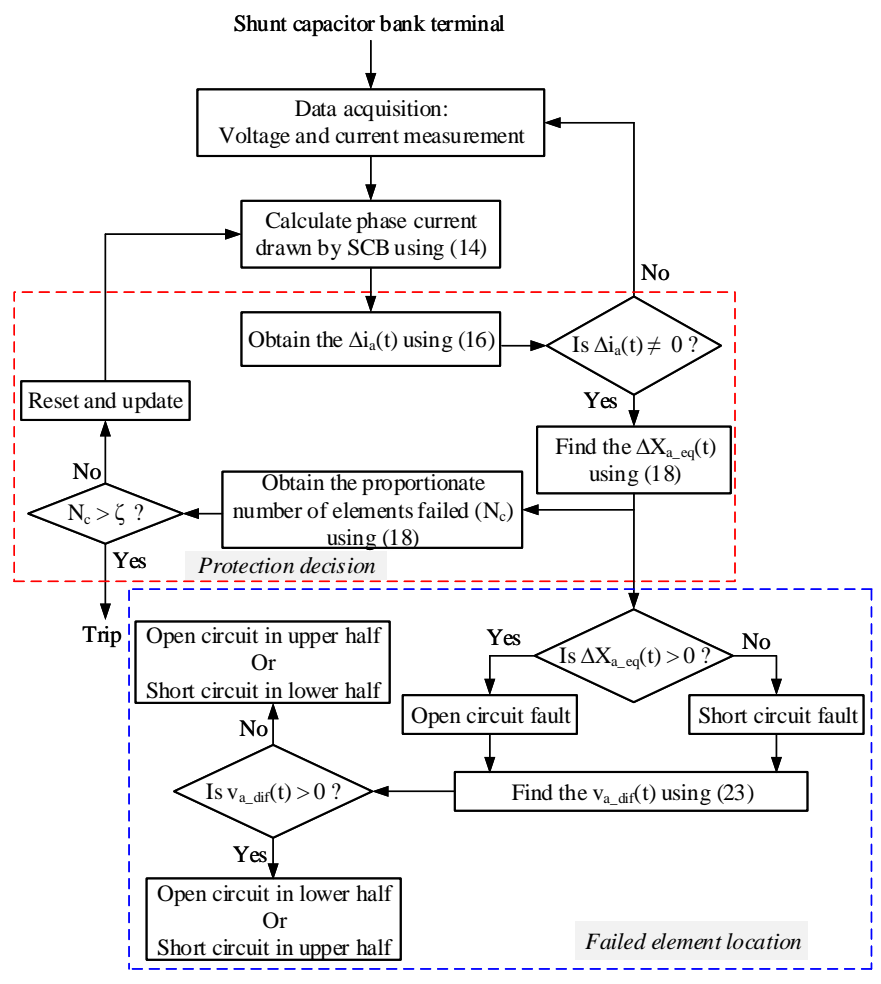

Fig. 5: Flow diagram of the proposed protection and fault location algorithms.

TABLE II: Various short circuit and open circuit faults in the SCB considered in Fig. 4

\begin{tabular}{|l|l|}
\hline Short circuit & Open circuit \\
\hline One element, two elements & One element (or, one branch) \\
three elements, four elements & two branches, one unit \\
five elements, six elements (or, one & two units, three units \\
branch or one unit or one group) & (or, one group or one phase) \\
\hline
\end{tabular}

digital signal of $1 \mathrm{MHz}$ samples is decimated to $4 \mathrm{kHz}$ rate for processing the incremental quantity based algorithm as shown in Fig.6 [14].

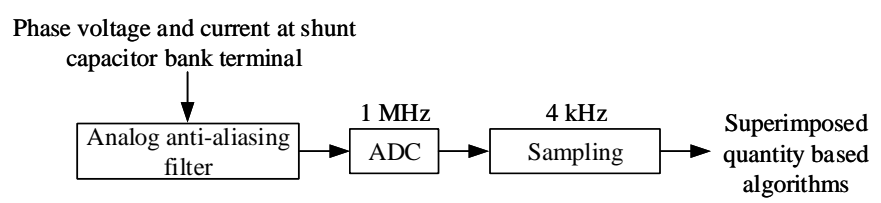

Fig. 6: Data acquisition for implementation of superimposed component.

The accuracy and sensitivity of the proposed method can be further enhanced by incorporating the auto-setting of $k_{t a p}$ and self-tuning of $C_{e q}$ features in each phase [18]. However, such provisions in the intelligent electronic device (IED) are not default (based on user's request).

\section{RESUlts}

For a $220 \mathrm{kV}, 50 \mathrm{~Hz}, 40 \mathrm{MVAR} \mathrm{SCB}$, the rated current flowing in each phase of $2 \mu \mathrm{F}$ equivalent capacitance is 79.8 A RMS. The threshold of $\Delta i_{a}$ is set as \pm 2.4 A, i.e. $\pm 3 \%$ 
TABLE III: System parameters

\begin{tabular}{|l|l|}
\hline System voltage & $220 \mathrm{kV}$ \\
\hline Base power & $100 \mathrm{MVA}$ \\
\hline Capacitive reactive power & $40 \mathrm{MVAr}$ \\
\hline System frequency & $50 \mathrm{~Hz}$ \\
\hline Each capacitor element & $13.33 \mu \mathrm{F}$ \\
\hline Capacitance per phase & $2 \mu \mathrm{F}$ \\
\hline Number of elements in a branch & 6 \\
\hline Number of branches in a unit & 3 \\
\hline Number of units in a group & 3 \\
\hline Number of groups per phase & 10 \\
\hline
\end{tabular}

of 79.8 A. The capacitive reactance offered by each phase is -j1592 $\Omega$. Using MATLAB/Simulink, the data are generated at a rate of $4 \mathrm{kHz}$. The parameters of the simulated system are provided in Table III. The protection and fault location features $\left(\Delta i_{a}(t), \Delta X_{a_{-} e q}(t)\right.$ and $\left.v_{a_{-} d i f}\right)$ are continuously being calculated and used for the protection and fault location. The tests demonstrated here include single and double Y-connected SCBs under balanced and unbalanced terminal voltages. A healthy SCB with unbalance voltage and faulted SCB with balance voltage experience unbalance current in the SCB. The proposed method distinguishes the internal unbalance correctly.

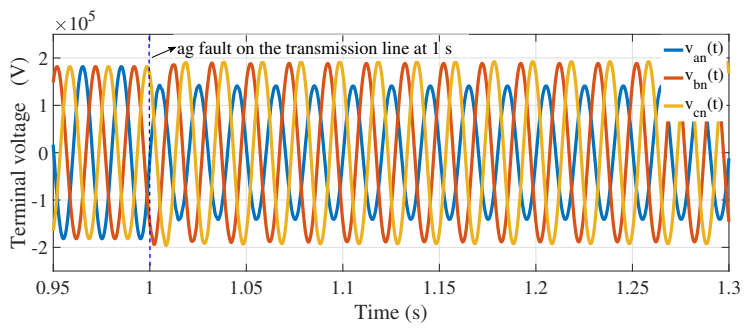

Fig. 7: Voltage unbalance at the SCB terminal.

\section{A. Element or unit failure detection and location in $S C B$}

1) Single Y-grounded/ungrounded SCB: The performance of the proposed method is verified for both grounded and ungrounded single Y-connected SCB during balance and unbalance voltages at the SCB terminal.

Unbalanced voltage at SCB terminal: Unbalance voltage at SCB terminal causes unbalance phase current even during no internal fault in the SCB. The voltage unbalance is simulated by creating a single line-to-ground (ag) fault at the middle of transmission line of $100 \mathrm{~km}$ emanating from a weak grid (short circuit ratio $=1.5$ [19]) with a fault resistance of $20 \Omega$ at 1 $\mathrm{s}$ of simulation run. The fault is not cleared intensionally to create a voltage unbalance at SCB terminal (Fig. 7).

During such an unbalance, one unit in the first group of phase-a of SCB is open circuited at $1.2 \mathrm{~s}$. The phase current is calculated using (14) and subtracted from the measured current to obtained the superimposed component $\Delta i_{a}$. The measured and voltage adaptive calculated currents in phasea are equal even during voltage unbalance as shown in Fig. 8. The corresponding superimposed current $\Delta i_{a}$ for one unit open is obtained using (16) and found to be sinusoidal component of 5.9 A peak value exceeding the threshold of 2.4 A (Fig. 9). Similarly, one branch and two branches in a unit of third group in phase-a are open circuited at $1.2 \mathrm{~s}$

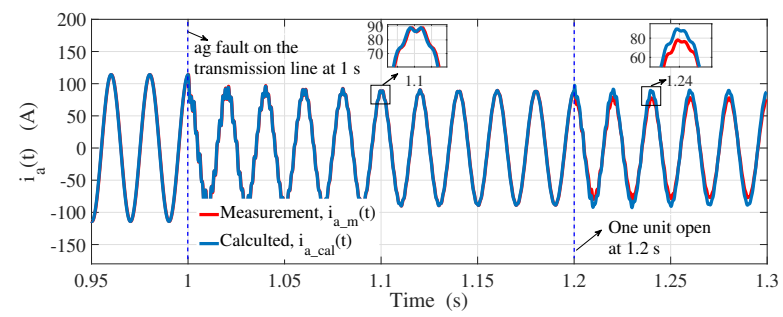

Fig. 8: Measured and calculated currents in phase-a of SCB for internal open circuit during voltage unbalance.

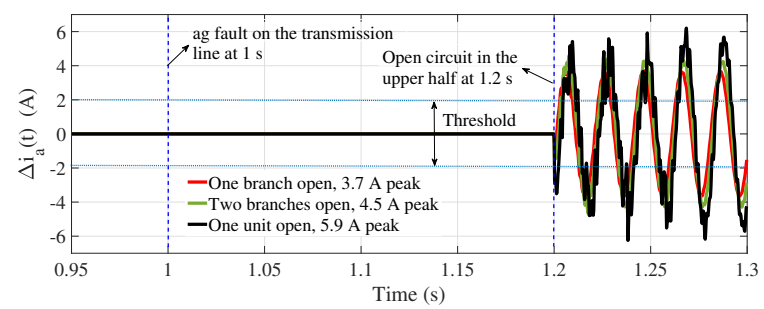

Fig. 9: $\Delta i_{a}$ for internal open circuit during unbalanced terminal voltage.

separately. The superimposed components $\Delta i_{a}$ for such cases are found to be sinusoidal of peak values $3.7 \mathrm{~A}$ and 4.5 A (exceed the threshold of $2.4 \mathrm{~A}$ ) as shown in Fig. 9. Also, zero $\Delta i_{a}$ is observed at $1 \mathrm{~s}$ during the transmission line fault as the proposed superimposed component is adaptive to voltage variation at SCB terminal. The change in reactances in timedomain $\Delta X_{a_{-} e q}$ for one branch, two branches and a unit open are found to be $19.87 \Omega, 45.75 \Omega$ and $79.4 \Omega$ respectively. The positive $\Delta X_{a_{-} e q}$ confirms the open circuit fault in the SCB.

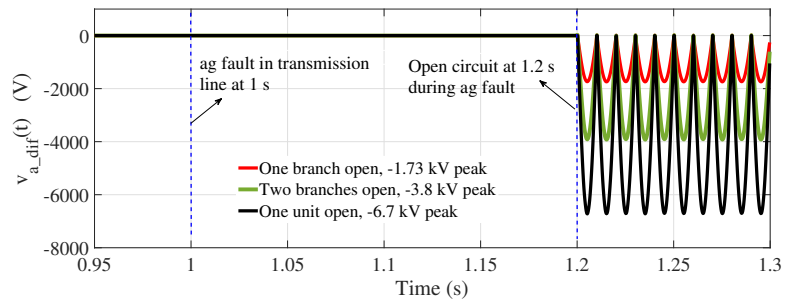

Fig. 10: $v_{a_{-} d i f}$ for open circuit in the upper half during unbalance terminal voltage.

The phase voltage is divided equally on both upper and lower halves of the SCB and found to be $63.5 \mathrm{kV}$ in each half during normal operation. The $v_{a_{-} d i f}$ for the above mentioned open circuit conditions is obtained using (22) and found negative as shown in Fig. 10. The corresponding $v_{a_{-} d i f}$ for one branch, two branches and one unit open are found to be -1.73 $\mathrm{kV},-3.8 \mathrm{kV}$ and $-6.7 \mathrm{kV}$ peak values respectively (Fig. 10). The negative $v_{a_{-} d i f}$ during open circuit fault corresponds to the upper one as faulted half.

With balanced voltage at SCB terminal: A strong grid (short circuit ratio $=6$ ) along with balanced loading is simulated to maintain the balanced voltage at SCB terminal [19]. One element, four elements in a unit and the entire unit in the second group in phase-a of SCB (Fig. 4) are short circuited at 
$1.2 \mathrm{~s}$ of the simulation run. The corresponding superimposed components $\Delta i_{a}$ are shown in Fig. 11. It is found that the method is able to detect single element failure in the SCB. For

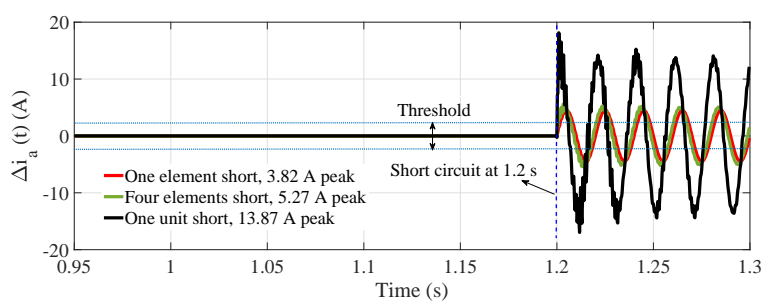

Fig. 11: $\Delta i_{a}$ during internal short circuit of capacitor elements.

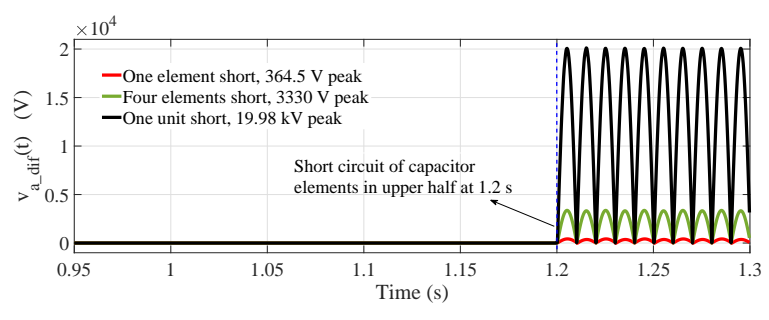

Fig. 12: $v_{a_{-} \text {dif }}$ for short circuit of capacitor elements in the upper half.

these conditions, the change in equivalent reactances in phasea $\Delta X_{a_{-} e q}$ during one element, four elements and one unit short are found to be $-3.47 \Omega,-28.86 \Omega$ and $-159.71 \Omega$ respectively. The negative $X_{a_{-} e q}$ confirms short circuit fault in the SCB. The voltage differences of both halves $v_{a_{-} \text {dif }}$ obtained for short circuit of one element $(364.5 \mathrm{~V})$, four elements $(3.33 \mathrm{kV})$ and one unit $(19.98 \mathrm{kV})$ in the second group in phase-a are shown in Fig. 12. The positive $v_{a_{-} d i f}$ for internal short circuit ensures the upper one of the SCB as the faulted half as per (22).

In case of single Y-ungrounded SCB as shown in Fig. 4, the neutral voltage $v_{n g}$ is not zero. The measured $v_{n g}$ is used in (22) and similar results are obtained as grounded case under both balanced and unbalanced voltages at the SCB terminal.

2) Double Y-grounded/ungrounded bank: The considered double Y-connected SCB is the parallel connection of two single Y-connected SCB (Fig. 4).

With unbalanced voltage at SCB terminal: A voltage unbalance is created by an ag fault in the middle of transmission line (connecting to a weak grid) at $0.9 \mathrm{~s}$ of simulation run. Three elements in a unit of third group of left leg of phase-a are short circuited at $1 \mathrm{~s}$. The corresponding $\Delta i_{a}$ is found with a peak value of $4.62 \mathrm{~A}$ as shown in Fig. 13. In another case, one unit is short circuited in the ninth group of the right leg in phase-a at $1.2 \mathrm{~s}$. The equivalent $\Delta i_{a}$ for one unit short is shown in Fig. 13 with a peak value of $13.7 \mathrm{~A}$ which exceeds the threshold of $2.4 \mathrm{~A}$. The corresponding $\Delta X_{a_{-} e q}$ for three elements short is $-15.89 \Omega$ and that for one unit short is $142.3 \Omega$. The negative signs classify the failure as short circuit fault in the SCB. The voltage differences $v_{a_{-}}$dif for the three elements short in left leg and one unit short in right leg are found positive $(1.42 \mathrm{kV})$ and negative $(-28.5 \mathrm{kV})$ respectively as shown in Fig. 14. This positive and negative $v_{a \_d i f}$ during short circuit fault identifies the faulted half as upper and lower respectively, which helps in expedite maintenance.

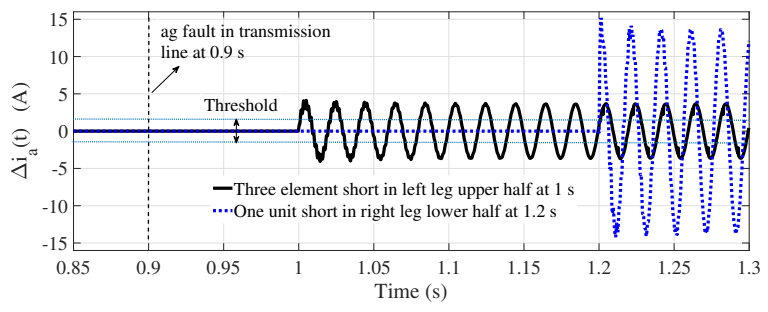

Fig. 13: $\Delta i_{a}$ for internal short circuit in double Y-connected SCB under unbalanced terminal voltage

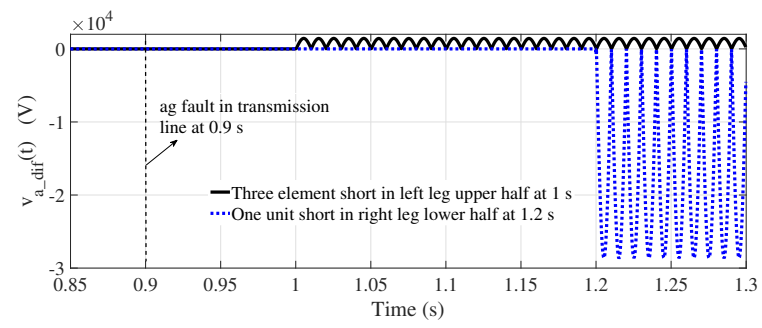

Fig. 14: $v_{a \_d i f}$ for internal short circuit in double Y-connected SCB under unbalance terminal voltage.

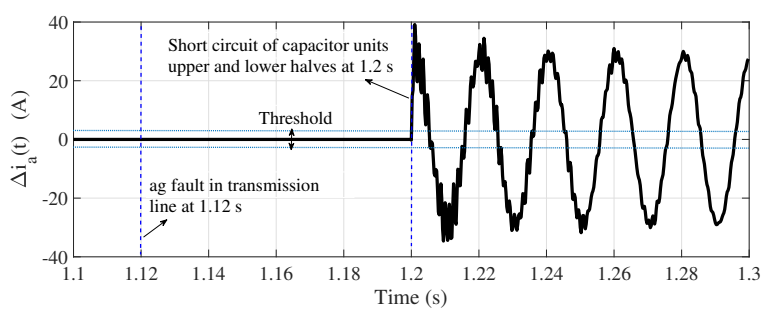

Fig. 15: $\Delta i_{a}$ during identical faults in the SCB.

\section{B. Performance of the method for identical faults in the $S C B$}

The performance of the proposed method is verified for identical faults in single Y-grounded SCB under the unbalance terminal voltage. The voltage unbalance is simulated as above case in section IV-A. In phase-a of SCB, a capacitor unit is shorted in both upper (third group) and lower (eighth group) halves at $1.2 \mathrm{~s}$. The corresponding $\Delta i_{a}$ is found $30.8 \mathrm{~A}$ peak as shown in Fig. 15 that detects the internal failure correctly. For such identical faults, the $\Delta X_{a_{-} e q}$ is found to be $-318.6 \Omega$ which (negative sign) ensures the failure as short circuit. The $v_{a_{-} \text {dif }}$ is zero as same number of unit is failed in both halves. However, the non-zero $\Delta i_{a}$ and zero $v_{a_{-} d i f}$ combinedly confirm the identical faults in the SCB.

\section{Performance during simultaneous faults in the SCB}

Sometimes two faults may happen in a phase in single Yconnected SCB or in two different legs of the same phase in double Y-connected SCB at the same time [20]. The performance of the proposed method is verified for such a simultaneous fault. In a single Y-connected SCB, a unit in 
TABLE IV: Comparative assessment of the proposed method with available methods for grounded Y-connected SCB

\begin{tabular}{|l|c|c|c|c|l|}
\hline Protection methods & $\begin{array}{c}\text { i. One element } \\
\text { short }\end{array}$ & $\begin{array}{c}\text { ii. One unit } \\
\text { short }\end{array}$ & $\begin{array}{c}\text { iii. Identical } \\
\text { faults }\end{array}$ & $\begin{array}{c}\text { iv. Simultaneous } \\
\text { faults }\end{array}$ & Remarks \\
\hline Proposed method & $3.82 \mathrm{~A}(\checkmark)$ & $13.87 \mathrm{~A}(\checkmark)$ & $30.8 \mathrm{~A}(\checkmark)$ & $13.2 \mathrm{~A}(\checkmark)$ & Works in all cases \\
\hline Phase voltage differential [6] & $0.135 \mathrm{~V}(\times)$ & $11.5 \mathrm{~V}(\checkmark)$ & $0 \mathrm{~V}(\times)$ & $1.53 \mathrm{kV}(\checkmark)$ & Works for ii and iv \\
\hline Neutral voltage unbalance [5], [6] & $0 \mathrm{~V}(\times)$ & $0 \mathrm{~V}(\times)$ & $0 \mathrm{~V}(\times)$ & $0 \mathrm{~V}(\times)$ & Does not work \\
\hline Phase current unbalance [5] & $0.18 \mathrm{~A}(\times)$ & $2.1 \mathrm{~A}(\checkmark)$ & $0 \mathrm{~A}(\times)$ & $0 \mathrm{~A}(\times)$ & Works for ii only \\
\hline Neutral current unbalance [5] & $0.15 \mathrm{~A}(\times)$ & $1.8 \mathrm{~A}(\times)$ & $0 \mathrm{~A}(\times)$ & $0 \mathrm{~A}(\times)$ & Does not work \\
\hline
\end{tabular}

second group and three elements in a unit in fourth group ( both in upper half of phase-a) are short circuited at $1.1 \mathrm{~s}$ in simulation. The superimposed component of current $\Delta i_{a}$ obtained using (16) is found as 13.2 A peak (Fig. 16) which identifies the simultaneous fault correctly. The $\Delta X_{a_{-} e q}$ for such fault is $-175.5 \Omega$ and the negative sign indicates internal short circuit fault in the SCB. The $v_{a \_d i f}$ during such a short circuit in phase-a is found to be positive with peak value of $26.7 \mathrm{kV}$ as evident from the Fig. 17 which also confirms the failed elements are in the upper half of the SCB. The

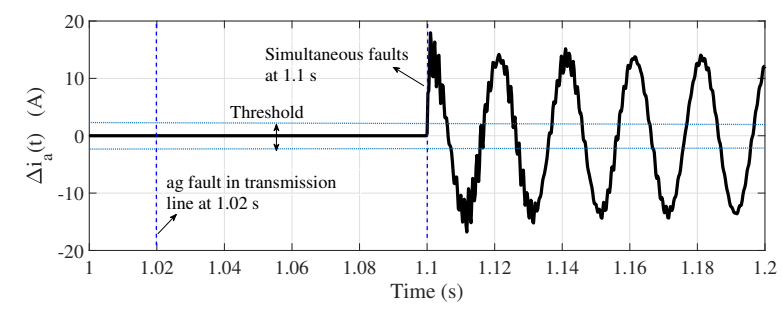

Fig. 16: $\Delta i_{a}$ during simultaneous short circuit of capacitor elements.

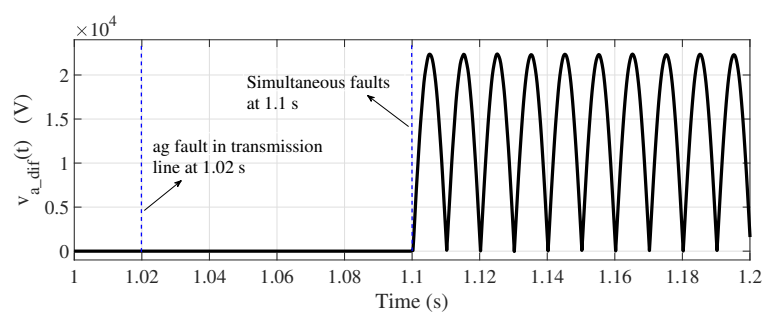

Fig. 17: $v_{\text {a_dif }}$ during simultaneous short circuit of capacitor elements.

protection decision is derived by monitoring the consistency of $\Delta i_{a}$ and $v_{a \_d i f}$ for five consecutive values which takes less than $2 \mathrm{~ms}$ at a sampling rate of $4 \mathrm{kHz}$.

\section{Sensitivity of the proposed method}

The protection sensitivity of the proposed method is studied by taking the derivative of instantaneous current with respect to equivalent capacitance. For example, using (16), it can be written as $\frac{\Delta i_{a}(t)}{\Delta C_{a}}=\frac{d v_{a n}(t)}{d t}$ where $\Delta C_{a}=\left(C_{a}^{\prime}-C_{a}\right)$ is the change in equivalent capacitance in phase-a. For short circuit of a single element, the $\Delta C_{a}$ is $0.307 \mu \mathrm{F}$. The $\frac{d v_{a}(t)}{d t}$ being $5.5 \mathrm{MV} / \mathrm{s}$ (typically, in the range of 4.2 to $6 \mathrm{MV} / \mathrm{s}$ ) in the system, the corresponding $\Delta i_{a}$ is 1.69 A. Similarly, open circuit of an element results $\Delta C_{a}$ of $0.223 \mu \mathrm{F}$ and $\Delta i_{a}$ of 1.15 A. Thus, the proposed method is sensitive to a single element failure. However, in phasor based methods [5], at least four elements need to be short or two branches to be opened to achieve reliable sensitivity.

\section{E. Comparative assessment with available methods}

The performance of the proposed algorithm is compared with the available methods for internal short circuit fault in grounded Y-connected SCB. Table IV provides the results of different protection methods for short circuit of one element, one unit, identical and simultaneous faults. The tick $(\checkmark)$ corresponds to successful identification of a fault and cross $(\times)$ indicates the unsuccessful operation. It is found that the proposed method works correctly for all the cases in contrast to available techniques.

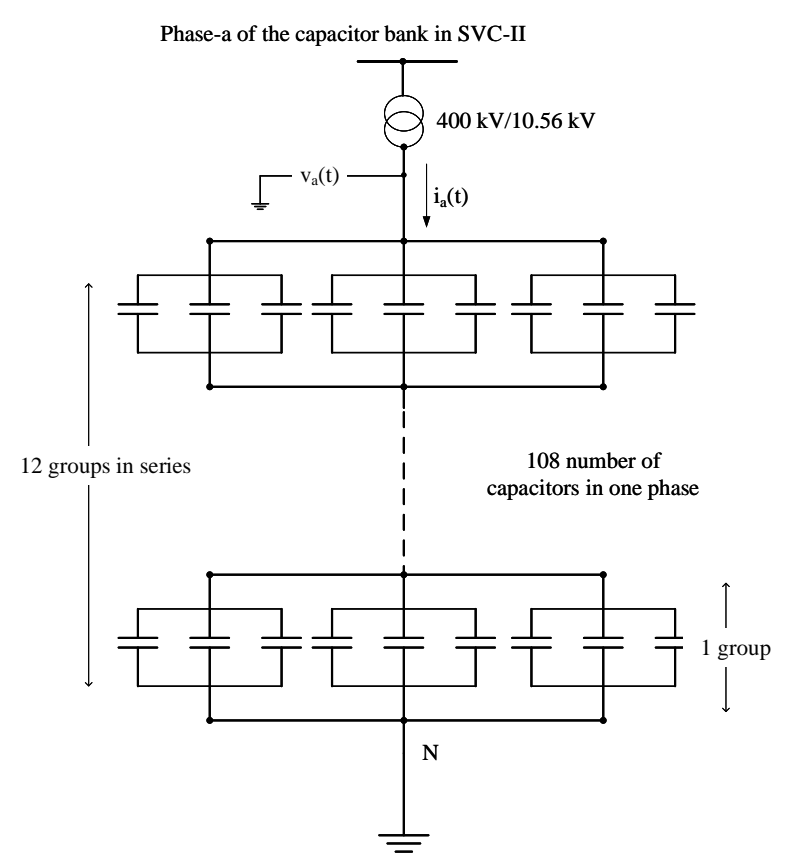

Fig. 18: Configuration of capacitor bank in phase-a of SVC-II in the $400 \mathrm{kV}$ substation.

\section{F. Validation of the proposed method using field data}

Static VAR compensators (SVCs) are in use in different substations in Indian Power grid. In one substation, the SVC consists of a shunt capacitor bank (SCB), thyristor controlled reactors (TCRs) and AC filters. The SCB of $60 \mathrm{MVAR}, 50 \mathrm{~Hz}$ is available at a $400 \mathrm{kV}$ substation through a $400 \mathrm{kV} / 10.56$ $\mathrm{kV}$ transformer in Indian power grid. Each phase of the Y-connected SCB consists of one bank with 108 capacitor elements and thus, the total number of capacitors in the SCB is 324 (Table V). The equivalent capacitance per phase of the 
TABLE V: Configuration and rating of the SCB in substation.

\begin{tabular}{|c|c|c|c|c|c|}
\hline $\begin{array}{l}\text { Number of capacitor bank } \\
\text { per phase }\end{array}$ & $\begin{array}{l}\text { Number of capacitor unit } \\
\text { per bank }\end{array}$ & $\begin{array}{l}\text { Total number of } \\
\text { capacitor in SCB }\end{array}$ & $\begin{array}{l}\text { Capacitance of } \\
\text { each unit }(\mu \mathrm{F})\end{array}$ & $\begin{array}{l}\text { Capacitance of } \\
\text { each phase }(\mu \mathrm{F})\end{array}$ & $\begin{array}{l}\text { Rating of } \\
\text { SCB }(\mathrm{MVAR})\end{array}$ \\
\hline 01 & 108 & 324 & 865.6 & 649.2 & 60 \\
\hline
\end{tabular}

SCB is $649.2 \mu \mathrm{F}$ and that of each capacitor unit is $865.6 \mu \mathrm{F}$. Phase-a capacitor elements in the SCB were short circuited and during the subsequent maintenance, two damaged units were found. The recorded terminal voltages at $10.56 \mathrm{kV}$ side of the transformer connected to SCB is shown in Fig. 19. It is observed that the voltage across the SCB is $16.73 \mathrm{kV}$ (higher than supply voltage due to the presence of series inductor). There is no change in terminal voltage during internal fault of capacitors in the SCB at $1.4 \mathrm{~s}$. Similarly, current in each phase of SCB at $10.56 \mathrm{kV}$ side is $1.96 \mathrm{kA}$ during normal condition as shown in Fig. 20. At $1.4 \mathrm{~s}$, a capacitor unit in the SCB is short circuited (stage 1 in Fig. 21) leading to $6.6 \mathrm{kA}$ RMS current and 29.5 kA RMS in stage 2 due to the failure of another unit. The current in phase-a rises due to internal short circuit of capacitor elements with phase-b and phase-c currents unaltered (Fig. 20).

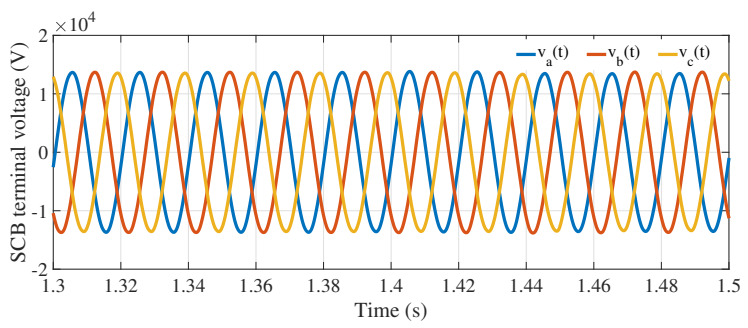

Fig. 19: SCB terminal voltages at $10.56 \mathrm{kV}$ side of the transformer.

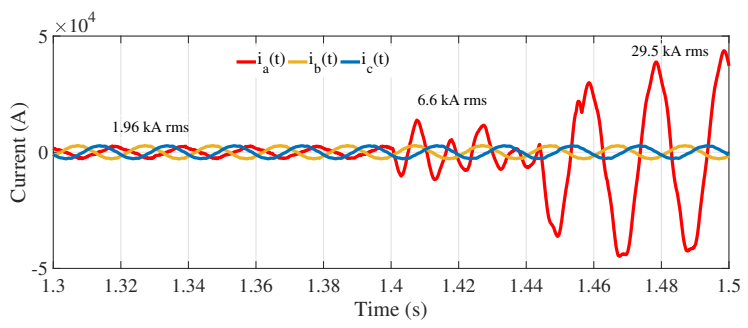

Fig. 20: Phase currents of SCB at $10.56 \mathrm{kV}$ side of the transformer.

With the field data available for SCB, the proposed method is validated for (i) internal fault detection in the SCB using superimposed component of current $\Delta i$ in each phase, (ii) type of internal fault identification using the sign of change in equivalent reactance in each phase, and (iii) number of elements failed in the SCB.

The data are sampled at a rate of $6.4 \mathrm{kHz}$. The measured and calculated currents of phase-a of the SCB are shown in Fig. 21 for the internal fault case. During the short circuit fault in SCB, the corresponding phase-a current rises (measured current, red color in Fig. 21). To obtain the superimposed component $\Delta i_{a}(t)$, prefault current is extended into the fault region (i.e. calculated current, blue color in Fig. 21). In stage 1, the superimposed current $\Delta i_{a}$ is found to be $8.7 \mathrm{kA}$ peak and

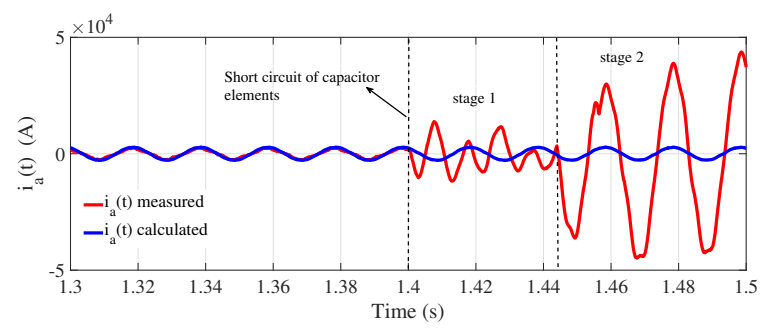

Fig. 21: Calculated and measured currents in phase-a of SCB.

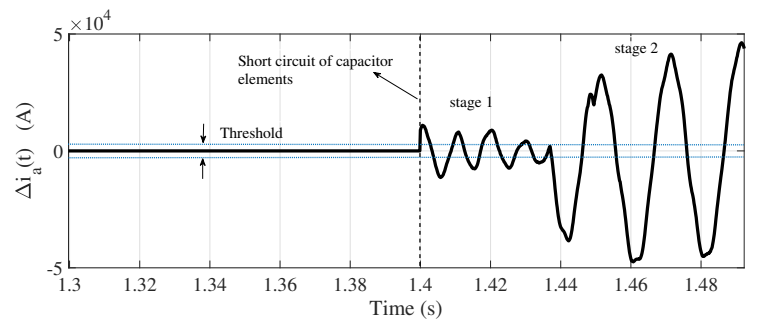

Fig. 22: Superimposed component $\Delta i_{a}(t)$ in phase-a of SCB.

the corresponding value in stage 2 is $41.2 \mathrm{kA}$ peak (Fig. 22). The non-zero $\Delta i_{a}$ confirms the internal fault during both stage 1 and stage 2 correctly. The change in equivalent reactances $\Delta X_{a_{-} e q}$ calculated are $-3.67 \Omega$ and $-7.24 \Omega$ during stage1 and stage- 2 respectively. The negative $\Delta X_{a_{-} e q}$ confirms the internal short circuit in the SCB. The values of $\Delta X_{a_{-} e q}$ correspond to short circuit of one unit in stage 1 and two units in stage 2. This finding is in agreement with the observation during maintenance of the SCB. In the installation of SCB, the mid-point tap measurements are not available. The faulted half could not be identified because of the unavailability of required voltage measurements. The above results demonstrate that the proposed method performs well even with field data.

In practice, for high voltage application of $\mathrm{SCBs}$, capacitor voltage transformers (CVTs) are used for voltage signal input to the relay. For internal fault in the SCB, there will be no transient issue with CVT because of not so high fault current and the grid being strong. Thus, the dependability aspect of the proposed algorithm is not being compromised while considering CVT. For external faults on transmission line (CVT with proper response) the proposed voltage adaptive superimposed current will work correctly. A close-in external fault may cause poor transient response of CVT which may look like an internal fault as the superimposed component will be high. Such a case may lead to incorrect decision which is compromising security of the relay. To overcome this, an additional check to be incorporated. This can be (i) in case of significant voltage dip implying an external fault, the proposed algorithm should be blocked, (ii) poor transient response of CVT can be confirmed from the ratio of measured phase current $\left(i_{a \_m}\right)$ to the derivative of phase voltage $\frac{d v_{a}}{d t}$. In case 
of proper CVT response $i_{a \_m}$ follows $\frac{d v_{a}}{d t}$ proportionately. The disproportionality of $i_{a_{-} m}$ to $\frac{d v_{a}}{d t}$ implies improper CVT response and thus, a close-in external fault, (iii) the phase change in $i_{a \_m}$ can be detected due to discharging of capacitor to the external fault in case of grounded Y-connected SCB. One and/or more of the above checks can be incorporated to identify the external fault with poor CVT transient. The proposed protection function for the SCB can be blocked during such situations.

\section{CONCLUSION}

In this work, a combined protection and fault location scheme for Y-connected SCB is proposed. The method uses instantaneous voltage and current to derive the sensitive protection decision within $2 \mathrm{~ms}$ for $4 \mathrm{kHz}$ sampling rate in a 50 $\mathrm{Hz}$ system. The change in equivalent reactance obtained using change in capacitance including its sign confirms the number of elements failed and type of failure. The sign of voltage difference of upper and lower halves in a phase of the SCB provides the information on faulted elements. The proposed protection method is adaptive to system voltage variation by incorporating accurate superimposed current calculation using SCB model. The performance of the method is tested for various cases including short circuit, open circuit, identical and simultaneous faults for both single and double Y-connected SCB, and found accurate. The comparative study with available techniques and validation with field data demonstrate the better accuracy and sensitivity of the proposed method. Protection and fault location of H-bridge SCB are considered as future work.

\section{REFERENCES}

[1] H. Jouybari-Moghaddam, T. S. Sidhu, M. R. Dadash Zadeh, and P. P. Parikh, "Enhanced fault-location scheme for double wye shunt capacitor banks," IEEE Trans. Power Del., vol. 32, no. 4, pp. 1872-1880, 2017.

[2] H. Jouybari-Moghaddam, T. S. Sidhu, M. R. Dadash Zadeh, and P. P. Parikh, "Shunt capacitor banks online monitoring using a superimposed reactance method," IEEE Trans. Smart Grid, vol. 9, no. 6, pp. 5554$5563,2018$.

[3] J. Wang, M. Ibrahim, Z. Gajić, and M. M. Saha, "Internal failure detection and protection on capacitor banks," in International Conference on Development in Power System Protection (DPSP), pp. 1-6, 2016.

[4] "C37.99-2000 - IEEE guide for the protection of shunt capacitor banks," IEEE Std., pp. 1-108, May 2000.

[5] C70 Capacitor Bank Protection and Control System, Instruciton Manual. GE Digital Energy, Feb. 2019.

[6] SEL-487V Relay, Capacitor bank protection, automation, and controlinstruction manual. Schweitzer Engineering Laboratories, INC., Aug. 2012.

[7] T. Patcharoen, A. Ngaopitakkul, C. Pothisarn, and M. Leelajindakrairerk, "Simulation analysis of the switching of $230 \mathrm{kv}$ substation shunt capacitor banks with a $6 \%$ series reactor for limiting transient inrush currents and oscillation overvoltage," Elect. Eng., vol. 100, pp. 435459,2018

[8] H. Jouybari-Moghaddam, T. Sidhu, I. Voloh, and M. Zadeh, "New method of capacitors failure detection and location in shunt capacitor banks," in Conference for Protective Relay Engineers (CPRE), pp. 1-10, 2018.

[9] S. Samineni, C. Labuschagne, J. Pope, and B. Kasztenny, "Fault location in shunt capacitor banks," in IET International Conference on Developments in Power System Protection (DPSP), pp. 1-5, 2010.

[10] H. Jouybari-Moghaddam and T. S. Sidhu, "A study of capacitor element failures in high voltage shunt capacitor banks," in Canadian Conference on Electrical and Computer Engineering (CCECE), pp. 1-4, 2017.
[11] H. L. Santos, J. O. S. Paulino, W. C. Boaventura, L. M. R. Baccarini, and M. L. Murta, "Harmonic distortion influence on grounded wye shunt capacitor banks protection: Experimental results," IEEE Trans. Power Del., vol. 28, pp. 1289-1296, July 2013.

[12] S. K. Buggaveeti, S. M. Brahma, W. C. Boaventura, L. M. R. Baccarini, and M. L. Murta, "Improved overcurrent protection of capacitor banks using mathematical morphology," IEEE Trans. Power Del., vol. 26, pp. 1972-1979, July 2011.

[13] E. O. Schweitzer, B. Kasztenny, A. Guzmán, V. Skendzic, and M. V. Mynam, "Speed of line protection - can we break free of phasor limitations?," in Conference for Protective Relay Engineers, pp. 448$461,2015$.

[14] E. O. Schweitzer, B. Kasztenny, and M. V. Mynam, "Performance of time-domain line protection elements on real-world faults," in Conference for Protective Relay Engineers (CPRE), pp. 1-17, 2016.

[15] P. Horton and S. Swain, "Using superimposed principles (delta) in protection techniques in an increasingly challenging power network," in Conference for Protective Relay Engineers (CPRE), pp. 1-12, 2017.

[16] B. Kasztenny, D. McGinn, and I. Voloh, "Enhanced adaptive protection method for capacitor banks," in IET International Conference on Developments in Power System Protection (DPSP), pp. 269-274, 2008.

[17] A. Goodarzi, M. Allahbakhshi, M. Tajdinian, and M. Popov, "Multicriteria protection scheme for online element failure detection in shunt capacitor banks," IET Gen., Trans. \& Distr., vol. 14, no. 19, pp. 4152$4163,2020$.

[18] B. Kasztenny, J. Schaefer, and E. Clark, "Fundamentals of adaptive protection of large capacitor banks - accurate methods for canceling inherent bank unbalances," in 60th Annual Conference for Protective Relay Engineers, pp. 126-157, 2007.

[19] C. W. Taylor, Power system voltage stability. McGraw-Hill, 1993.

[20] S. P. Polisetty and S. Das, "Novel method for location of internal faults in ungrounded double wye shunt capacitor banks," IEEE Trans. Power Del., available in early access, 2020.

\section{BIOGRAPHIES}

Rabindra Mohanty (Member, IEEE) received the B.Tech. degree in Electrical Engineering from Veer Surendra Sai University of Technology, Burla, India, in 2011. He did his M. Tech. in Power and Energy Systems and Ph.D. degree in Electrical Engineering at Indian Institute of Technology Kharagpur, India in 2014 and 2018 respectively. He is currently a postdoctoral researcher in the division of Electric Power Engineering at Chalmers University of Technology, Gothenburg, Sweden.

His research interests include power systems protection, renewable energy integration, protection and control of microgrids.

Ashok Kumar Pradhan (Senior Member, IEEE) received Ph.D. degree in Electrical Engineering from Sambalpur University, Sambalpur, India, in 2001. He is a Professor with the Department of Electrical Engineering, Indian Institute of Technology Kharagpur, India, since 2002. Prof. Pradhan is a Fellow of Indian National Academy of Engineering (INAE) and The National Academy of Sciences (NASI), Allahabad, India.

His research interests include Power System Relaying and Monitoring. 